\title{
CHAMBER ENSEMBLE OF THE BAROQUE ERA: SPECIFICS AND TYPOLOGY
}

\section{Irina Polskaya}

\section{INTRODUCTION}

One of the fundamental, widespread and valuable areas of musical art, is the chamber ensemble, whose genre formation is largely associated with the Baroque era. The phenomenon of baroque music has long attracted the close attention of many European, American and domestic scholars who study the history of European musical culture and disclose the characteristic features of its development at this crucial stage. In modern musicology, the level of Baroque art research is quite high. However, the problems associated with the phenomenological and semantic specifics of the chamber ensemble of this period, historical and theoretical aspects of the main ensemble genres formation and performer's functional role models, still stay one of the least studied in music science.

This is what determines the relevance and novelty of this study, devoted to the specifics and typology of the Baroque era chamber ensemble as well as to the identification of its initial stage basic principles. This issue, almost unstudied in Ukrainian musicology, was first presented in the author's works summarizing the results of her lond-term work in the field of an ensemble's theory and history: the monograph "Chamber ensemble: history, theory, aesthetics" and the doctoral dissertation "Chamber ensemble: theoretical and cultural aspects"2. Source database of the study consists of researches in the field of music history and individual ensemble genres (first of all works of C. Ph. E. Bach, E. M. Braudo, M. Bukofzer, I. Bialyj, L. S. Ginzburg, T. Dapkiashvili, M. Hurd, E. H. Meyer, E. Sorokina， D. Stevens, W. J. von Wasielewski etc.).

The scientific novelty of the research is that the chamber ensemble of the Baroque era is first presented as a systemic phenomenon, its phenomenological, semantic and communicative specifics are substantiated, its main types and genre models, ways and methods of their formation are revealed. The aim of the research is the conceptualization of the Baroque

\footnotetext{
1 Polskaya, I. I. (2001). The Chamber Ensemble: History, Theory, Aesthetics: Monograph. Kharkov: KhDAK.

${ }^{2}$ Polskaya, I. I. (2003). Chamber Ensemble: theoretical and culturological aspects (Hab. Dr.), Kyiv, P. I. Tchajkovsky National Musical Academy of Ukraine.
} 
chamber ensemble's phenomenon and the typologization of its genre manifestations. The research tasks are: 1) to reveal the historical specifics of an ensemble genres formation in the Baroque era; 2) to identify the basic principles of genre differentiation of an ensemble music of this period; 3 ) to reveal the organological specificity of the baroque ensemble; 4) identify the ways of instrumental ensemble genre invariant formation during the Baroque era; 5) to characterize the leading functional and role models of the baroque ensemble; 6) to reveal the semantic specificity of the "solo" concept in the Baroque music; 7) to identify the organological and communicative specifics of the clavier ensemble formation.

The research methodology is based on the integrative combination of general scientific and special musicological methods and combines historical and theoretical approaches. The main methods and approaches used are: historical (historical-genetic, historical-typological), culturological, systemic, contextual, comparative, terminological, structural-functional, genre, style, performing analysis. The logic of the statement's presentation is determined by the dominance of the general-to-particular principle, which contributes to the fulfillment of scientific tasks and the achievement of the main study aim.

In the text of the study, special terminology first developed and put into scientific circulation by the author is widely used (terms: "parallel-variant performance of an ensemble parts", "chamber-clavier genres", "multiclavier and monoclavier ensemble", "horizontal and vertical sound volume expansion of the keyboard instruments"). It should be noted that for today the holistic historical and theoretical chamber ensemble concept, created by the author, and all the associated definitions (including those abovementioned) are used as basic in most domestic studies of an ensemble problematics.

\section{Baroque ensemble music: principles of genre differentiation}

In the baroque era $\left(17^{\text {th }}\right.$ century - first half of the $18^{\text {th }}$ century) the process of the "genre evolution of the chamber ensemble, associated with the invariant formation of the instrumental ensemble <...> has began. The process of the chamber ensemble types formation of this era is marked by a special diversity of their embodiment, freedom of all genre transformations and interactions" ${ }^{3}$. The highest artistic achievements of this era are represented by the creative heritage of Antonio Vivaldi, Arcangelo Corelli, Johann Sebastian Bach, Dieterich Buxtehude, George Frideric Handel, Henry Purcell, Georg Philipp Telemann and many others.

\footnotetext{
${ }^{3}$ Polskaya I. I. (2012). Chamber Ensemble. The Encyclopedia of Modern Ukraine. Vol. 12. Kyiv: Institute for Encyclopedic Research by National Academy of Sciences of Ukraine, p. 113.
} 
Ensemble music dominated in spiritual and secular music of the Baroque era. Its widespread distribution in the era's cultural life is convincingly confirmed by the numerous paintings of famous Italian, Flemish, German painters depicting the groups of musicians which belonged to different society stratums. Often there are also picturesque images of angels and mythological heroes playing in the ensemble.

Mainly in the Baroque era the archetype of a modern chamber ensemble began to form, designed not for large rooms, but for an intimate room setting and representing the brightest manifestation of a chamber music, designed for connoisseurs and art lovers.

In the $17^{\text {th }}$ century, a process of fundamental genre differentiation of chamber ensemble music takes place, its semantic division into two main spheres - ecclesiastical (church) and chamber itself (which is associated with the emergence and approval of an instrumental sonata genre in its Baroque typological forms - Sonata da chiesa and Sonata da camera) has occured.

In this period, the process of the genre formation of a chamberinstrumental ensemble music takes place in the context of its existence in two main areas - ecclesiastical (church) and chamber itself. This process is associated with the emergence and approval of the instrumental sonata genre in its baroque typological forms - Sonata da chiesa and Sonata da camera. The main substantive difference between these genres was that, as Michael Hurd points out: "A solo or trio sonata that consisted entirely of movements in dance pattern was called a Chamber Sonata (Sonata da camera). One that incorporated more dignified, abstract movements, was referred to as a Church Sonata (Sonata da chiesa)" ". However, in practice, according to the same researcher, this distinction "was not always strictly maintained, though most church sonatas begin with a solemn adagio, followed by an allegro in fugal style" 5 .

There were other fundamental differences between these types of baroque sonatas - semantic, genre-communicative, organological, due to quantitative and qualitative features of their performing composition and situational context. Thought, if Sonata da chiesa was intended "for concert performance in a church, on an organ, with the participation of a large number of performers" forms, was performed "in salons, for a narrow circle of listeners, or in courtier concerts with a small cast accompanied by a harpsichord"7.

\footnotetext{
${ }^{4}$ Hurd, Michael. An outline History of European Music. London, 1968, p. 55.

${ }^{5}$ Ibid.

${ }^{6}$ Ibid.

${ }^{7}$ Dapkviashvili T. (1989). Chamber instrumental ensembles and basic principles of ensemble performance. Tbilisi: Helovneba, p. 5.
} 
The contrast between the genres of Sonata da camera and Sonata da chiesa was based, according to Professor L. S. Ginzburg, first of all, "on the style and character of each genre, on its fitness for a particular type of musical practice. If the da chiesa genre was intended to be performed in a temple with the participation of an organ and a large number of performers and was more strict, the da camera genre was suitable for home music production, usually using a harpsichord and a limited number of musicians, and was closely associated with domestic, often dance music" $"$. According to the scientist, it is precisely "coexisting in the $17^{\text {th }}-18^{\text {th }}$ centuries genres of sonata da camera and sonata da chiesa $\langle\ldots\rangle$ and their interpenetration contributed to the enrichment of both genres and gradually led to the formation of the classical instrumental sonata for two equivalent instruments" ${ }^{\prime \prime}$ - a genre that synthesized the best features of both its predecessors and at the same time fundamentally different from them.

The genre differentiation of the Baroque era chamber ensembles occurred not only in the sphere of their functioning (ecclesiastical or secular), but also according to other criteria, one of the most important was the number of solo voices. Proceeding from this, the main genres of baroque chamber-ensemble music were solo sonata and trio sonata.

Describing the emergence of the Baroque era chamber music, Michael Herd emphasizes on these genres fundamental role: "Chamber music is to be founded under two main headings. First, the solo sonata, which consists of a solo instrument (usually, a violin) supported by a figured bass accompaniment, played by the usual combination of harpsichord (or organ) and string bass. Second, the trio sonata, employing two solo instruments, with continuo support" $"$.

It is obvious that both of these chamber music genres, differing from each other functionally (in the context of instrumental parts interaction and their internal hierarchy), are similar in structure and performing constitution. The main difference between them lies inside the role of the second stringed instrument, performing in one case the functions of the bass accompaniment, and in the other - a melodic voice (soloist).

The ensemble genres of solo and trio sonatas developed mostly in Italy and Germany. The most outstanding masters of the genres representation were in Italy - Arcangelo Corelli (1653-1717), Antonio Vivaldi (1678-1741), Francesco Saverio Geminiani (1687-1762), Pietro Antonio Locatelli (1695-1764);

8 Ginzburg L.S. (1979). Chamber Music in the modern musical practice. Chamber Ensemble: Pedagogic and Performing Art. Moscow: Muzyka, p. 160.

${ }^{9}$ Ginzburg L. S. (1979). Chamber Music in the modern musical practice. Chamber Ensemble: Pedagogic and Performing Art. Moscow: Muzyka, p. 161.

${ }^{10}$ Hurd, Michael. An outline History of European Music. London, 1968, p. 55. 
in Germany - Georg Philipp Telemann (1681-1767) and Johann Sebastian Bach (1685-1750), in England - Henry Purcell (1659-1695), in France - Jean-Marie Leclair (1697-1764). A significant contribution to the development of an ensemble genres (primarily trio sonatas) was also made by many other outstanding musicians of that era - Evaristo Felice Dall'Abaco (1675-1742), Francesco Antonio Bonporti (1672-1749), Tomaso Giovanni Albinoni (1671-1751), Antonio Veracini (1659-1733), Giuseppe Torelli (1658-1709), Giuseppe Tartini (1692-1770), Carlo Antonio Marino (1670-1735), Giulio Taglietti (1660-1718), masters of the Bologna Composer School, who, according to M. Bukofzer, "held the key position in the field of chamber music" ": Pietro degli Antonii (1639-1720), Giovanni Battista Bassani (1650-1716), Tomaso Antonio Vitali (1663-1745), Giuseppe Aldrovandini (1671-1707), Giuseppe Matteo Alberti (1685-1751) and others. Remarkable examples of the chamber ensemble music are presented by Dieterich Buxtehude (ca. 1637-1707), George Frideric Handel (1685-1759) and by a number of their contemporaries.

The dominant structural-genre model of the 17 th century chamber music becomes the trio sonata. The founder of this genre was the famous Italian composer Salomone Rossi Hebreo (ca. 1570-1630) - one of the founders of the chamber-instrumental ensemble in the music of the 17th century. It was he who created in 1607 the Sinfonie e Galiarde which is, as M. Bukofzer notes, the first trio sonata ever ${ }^{12}$. Following Rossi, Biagio Marini (1594-1663) addressed the genre of trio sonatas in his composition "Affetti musicali" (1617). Afterwards, Giulio Belli (ca.1560 - later 1621), Giovanni Battista Riccio (1570-1630), Francesco Turini (1589-1656), Tarquinio Merula, (1594/1595 - 1665), Francesco Usper (1561-1641), Stefano Bernardi (1577-1637), Ottavio Grandi (? ca. 1610-1630), Pellegrino Possenti (1597-1649), Girolamo Frescobaldi (1583-1643), Giovanni Battista Buonamente (ca. 1595-1642) and many other composers followed his example.

In the Baroque era there were no fundamentally semantic gradations between solo, ensemble, concert performing genres, which were on the level of primary syncretism. The early stage in the development of European instrumentalism is also characterized by a certain quantitative undifferentiation of orchestral, concert, and ensemble genres. The process of future independent instrumental music genres formed on their basis and was long lasting and gradual.

To identify the specifics of the baroque period in the chamber ensemble evolution, interpretation of the genre differences between solo

\footnotetext{
${ }^{11}$ Bukofzer. Manfred. Music in the Baroque Era: From Monteverdi to Bach. London, 1964, p. 232 .

${ }^{12}$ Ibid, p. 53.
} 
music (in its modern sense), music for a solo instrument with an accompaniment and pure ensemble music during the $17^{\text {th }}-18^{\text {th }}$ centuries should be noticed as a fundamentaly important question. Such a functional differentiation, familiar to nowadays, seems to be an anachronism for the baroque period of genre evolution, since the process of historical formation, stabilization of each of these genre types has just begun and was very far from final crystallization.

At this development stage, the processes of ensembles formation as such and ensembles based on the principle of "solo accompaniment" went in inextricable unity, complementing each other. From the point of the intraensemble hierarchy of performing parties, their role functions and ensemble writing, many Baroque chamber-ensemble compositions seems to be compositions for a solo instrument with an accompaniment, rather than ensembles themselves. During this period close diffuse interaction of solo and ensemble genres, purely ensemble music and music for solo instruments with accompaniment had been taken place.

Modern ideas about these phenomena are based on such fundamental principles as: 1) the personal level of interaction; 2) "one performer - one party"; 3) role equality of an ensemble partners - role inequality of a solo and accompaniment parties in the musical hierarchy ${ }^{13}$. Semantic transformation of solo and ensemble genres,as well as their definition, crucial for performing and composing ability, is associated with the historical process of the gradual approval of these principles.

Close attention is drawn to the semantic transformation of the term "solo" in the musical culture of the $17^{\text {th }}-20^{\text {th }}$ centuries.

In various publications it was repeatedly noted by the author that chamber music of its early period was ensemble-like; the solo tradition in performance was born, gradually "budding" from the latter by strengthening the role of solo episodes ("concertini") or a sharp change in the functional ensemble hierarchy in favor of one instrument or another (violin, clavier) or voice ${ }^{14}$. The concepts of "solo performance", "solo sonata" in the Baroque era were rather vague and included both individual performance of music (works intended for a single musician-soloist) and joint performance for a soloist with an instrumental accompaniment, which could be obligatory (for example, harpsichord continuo) or possible (ad libitum). At the same time,

13 Polskaya I. I. (2001). The Chamber Ensemble: History, Theory, Aesthetics: Monograph. Kharkov: KhDAK, p. 114.

${ }^{14}$ Polskaya I. I. (2004). The Genre Specifics of the Chamber Ensemble of the Baroque era (semantic and functional role aspects). The Bulletin of the International Slavic University. Series: Art Studies, no. 1, pp. 44-45. 
in $17^{\text {th }}-18^{\text {th }}$ centuries a clear border between solo music with and without accompaniment still did not exist ${ }^{15}$.

In the course of historical development, fundamental changes in the content of a numerous genre concepts (including "solo sonata") and their definitions has occurred. Thereby, as Manfred Bukoftser notes in the book "Music of the Baroque Era", during the historical development of the musical art "The terminology of the sonata literature has created considerable confusion"16.

Among the concepts that have undergone a semantic transformation is the term "solo sonata". Considering this problem, M. Bukoftser emphasizes the historical differences in the interpretation of the concepts of "solo sonata" and "trio sonata" related to the number of performers and ensemble parts: "According to the most consistent usage the sonatas were distinguished by the number of essential parts, including the continuo, as sonatas a due, a tre, a quatro. Since, however, the continuo was often taken for granted, the sonata $a$ due was also called solo sonata, a term that has a misleading connotation today. And while the sonata for two ornamental instruments was known usually as trio sonata or sonata a tre, the corresponding vocal form was inconsistently termed chamber duet, obviously because of the difference in medium between the upper parts and the bass. The performance even added to the confusion because the continuo required at least two players, so that the "solo sonata" called for three, the trio sonata for four players. It must be remembered that the number of structural parts in baroque chamber music did not coincide with the number of performers, and that the continuo was always understood, so much so that the exceptional sonatas for violin solo without accompaniment were always expressly marked senza continuo" ${ }^{\prime 17}$.

Until the era of Bach and Handel, a duet sonata was performed with equal success, as Denis Stevens points out "by either less or more people than its title implies. It was, in fact, a sonata for solo violin and continuo, and the music was printed in separate books - one containing the violin part, and other the bass. This bass part - book, which usually assisted the harpsichordist by indicating chords numerically as well as giving the actual left-handing part, was often played by a viola da gamba or cello in addition to the harpsichord" ${ }^{18}$. Thus, genre division could be made both by the total number

\footnotetext{
${ }^{15}$ Polskaya I. I. (2004). The Genre Specifics of the Chamber Ensemble of the Baroque era (semantic and functional role aspects). The Bulletin of the International Slavic University. Series: Art Studies, no. 1, p. 45.

${ }^{16}$ Bukofzer. Manfred. Music in the Baroque Era: From Monteverdi to Bach. London, 1964, p. $51-52$.

${ }^{17}$ Ibid, p. 52.

${ }^{18}$ Stevens, Denis Duet Sonatas without wind instruments (from 1700) / Chamber music. London, 1970, p. 255.
} 
of performing parties, and by the number of exclusively melodic voices (excluding continuo).

Consequently, in the musical practice of that era, the term "solo sonata" could be applied both to the solo (sole) performance and to the ensemble duet (with the participation of the harpsichord continuo) and accordingly, in contrast to the modern meaning, to extend on compositions for a different number of performers (from one to three) - providing that the leading role in the ensemble belongs to one - soloing - instrument.

It is precisely due to this interpretation of "solo" and "solo sonata" concepts an undifferentiated idea of solo and ensemble performance (which have already been discussed) of the $17^{\text {th }}-18^{\text {th }}$ centuries musical theory arises. During this period the chamber-instrumental ensemble tradition was forming, and there was no impassable line between solos, duets, trios, quartets, etc. At the request of the performers, one ensemble could always be transformed into another.

The same rule applies equally (by analogy) to all varieties of baroque ensembles written in the genre of trio sonatas and intended for execution by several (three or more) participants, including continuo. I. Bialyj in relation to the "trio" concept notes typological, generalizing character of Baroque genre designations, which doesn't reflect the specifics of performing groups: "Until the last quarter of the eighteenth century, the designation "trio" was distributed as the general name for trio sonatas, in which $\langle\ldots\rangle$, the number of individual instrumental parts could range from one to five" ${ }^{\text {"19 }}$.

The genre specificity of the trio sonata is based on the action of the so-called "trio principle" (I. Bialyj terminoligy ${ }^{20}$ ) or "trio models" based on a three-voice texture. Role functions of an ensemble parts within the trio model are predetermined: more mobile melodic voices in the upper or middle register interacted with each other, balancing the smooth bass line. I. Byalyi notes that "in conditions of instrumental writing universality of the baroque period, in the absence of "typical", stable orchestral and ensemble compositions, the trio principle characteristic was purely textural, indicating the number of voices, but not the number of instruments" 21 .

Thus, the baroque genre designations, due to a priori character of the textured interaction patterns of an obligatory melodic voices, shouldn't be considered from the standpoint of a modern musical thinking with its ideas about an ensemble roles predestination concerning the instrumental parts with

${ }^{19}$ Bialyj I. (1989). From the History of the Piano Trio: Genesis and the Formation of the Genre. Moscow: Muzyka, p. 9.

${ }^{20}$ Bialyj I. (1989). From the History of the Piano Trio: Genesis and the Formation of the Genre. Moscow: Muzyka, p. 9.

${ }^{21}$ Ibid. 
unconditional quantitative identification of the concepts of "performer ensemble parts". During this period, quantitative factors of genre formation did not yet have fundamental significance.

\section{Baroque chamber ensembles: organological specificity and functional role models}

As it was repeatedly emphasized by the author earlier, "Specificity of the baroque chamber ensemble is caused by a quantitative and timbre variability and instability of performing groups ${ }^{22}$. The most important feature of an ensemble Baroque music is the imbalance of performers number, textured voices, ensemble parts and the purely textural nature of genre designations that does not reflect the specifics of performing composition characteristics. At the request of the participants, the ensemble could always freely transform into another one. The number of an ensemble votes is not always correlated with a number of an ensemble parties and wasn't related to the number of an ensemble members. A characteristic feature of a chamber and instrumental music of the $17^{\text {th }}$ century development is "the absence of established, stable ensemble types with a firmly established composition of participants. The performing compositions of that era are variegated combinations of stringed, wind, keyboard and plucked instruments" 23 .

In the Baroque era there was an intensive development of instrumental performance, which predetermined the further formation of its various future directions and genre spheres - chamber ensemble, orchestra and concert. Ensemble music organically included an organ performance by Sonata da chiesa.

In this period, a sharp distinction between string, clavier, or mixed ensembles by qualitative (timbre-acoustic or textured) parameters did not yet arise. There was a stable tradition of "parallel-variant" 24 performance of an ensemble parts with an equal coexistence of several timbre modifications.

In accordance with an orientation toward the fundamental possibility of timbre and functional transformations, interchanges of instruments (especially strings and keyboards) in chamber ensembles, determined, in particular, by the functional assignment of the trio model, were widely practiced. Such interchanges were a kind of a compromise between 1) the preservation of performing freedom in timbres and instruments choices that existed in the

${ }^{22}$ Polskaya I. I. (2012). Chamber Ensemble. The Encyclopedia of Modern Ukraine. Vol. 12. Kyiv: Institute for Encyclopedic Research by National Academy of Sciences of Ukraine, p. 113.

${ }^{23}$ Bialyj I. (1989). From the History of the Piano Trio: Genesis and the Formation of the Genre. Moscow: Muzyka, pp. 9-10.

24 Polskaya I. I. (2001). The Chamber Ensemble: History, Theory, Aesthetics: Monograph. Kharkov: KhDAK, p. 118. 
Middle Ages and Renaissance music, and 2) the relative consolidation of the role participation of certain instruments (primarily the continuo harpsichord), or 3) the approximate fixation of the proposed options like replacements (harpsichord - lute, violin - flute, viola d'amur - violin, viola da gamba cello, harpsichord - spinet - virginal, melodic instruments - second harpsichord, etc.). When playing trio sonatas, ensemble group of two violins and a Basso continuo, performed by an organ (in Sonatas da chiesa) or a keyboard instrument (harpsichord, spinet) was the most common. Trio sonatas for mixed composition (with the participation of wind instruments) were also popular.

For baroque chamber ensembles, the most typical interchanges are: 1) instruments that performed the functions of basso continuo (lute and harpsichord); 2) melodic instruments playing the treble part (violin - viola, violin - flute); 3) melodic instruments playing the bass part (viola da gamba cello); 4) melodic string instruments and a second harpsichord (in clavier duets such as "croisées" by François Couperin). F. Couperin in the preface to "Concerts royaux" even offers to replace the clavier not only with string, but also with wind instruments: "The following compositions <...> are suitable not only for harpsichord, but also for violin, flute, oboe, viola and bassoon" 25 .

The organological aspect of the Baroque ensemble culture functioning is determined by the historical turning point in the development of musical instruments. The formation of a chamber ensemble genres went in several different directions, produced by the sociocultural transformations of individual instrument's roles (viola, violin, cello, harpsichord), the functional hierarchy of their ensemble parts and interpretation of a genre semantics. In the course of ensemble genres historical evolution, the ideas about various ensemble functions content, and about the instruments the ensemble should be fulfilled with, have repeatedly changed, sometimes diametrically opposed.

So, the functional role relationships of melodic (usually string) and harmonic instruments in the ensemble, the functions of soloing and accompaniment were not assigned to certain instruments and parts. In the early stages of an ensemble formation, the role of a melodic solo usually belonged to the violin, flute or viola d'amor, and the accompaniment functions were traditionally performed by stringed, plucked (harmonic) instruments - lute, harp, guitar. Later, the role of a harmonic instrument passed to the continuo harpsichord, to which the stringed bass - the viola da gamba, violone or the cello, often joined. At the same time, in parallel there

${ }^{25}$ Ivanov-Boretskiy M. V. (ed.) (1934). Materials and documents on the history of music. Vol. 2: XVIII century (Italy, France, Germany, England). Moscow: Muzgiz [State Music Publishing House], p. 280. 
were performance models with a fundamentally opposite functions, where the leading role in the ensemble belonged to the harpsichord, and the secondary to the strings or flute.

The most important direction of the Baroque ensemble culture development appeared to be the formation of the genre of an instrumental ensemble with the participation of the clavier. The process of their formation, which took place during the 17 th -18 th centuries, was associated on its early stages with the development of the role interaction principles, common to all performing ensemble varieties, while maintaining a relative freedom of a direct choice of specific instruments (tones) and voices, as well as the total number of performance possible participants. In that era, the historical paths to all instrumental chamber-clavier ${ }^{26}$ genres formation- duets, trios, quartets were unified, associated with the implementation of an artistic methods and aesthetic principles common to this type of musical performance.

A significant role in the crystallization process of a chamber-clavier ensembles was introduced by the methods of genre transformation "from intavolature" and "from colla parte", which were widespread in the $16^{\text {th }}$ early $17^{\text {th }}$ centuries, and contributed to the formation of an obligate clavier part in the instrumental ensemble.

Communicative and functional interpretation of an ensemble role of the harpsichord (the piano) in the $17^{\text {th }}-18^{\text {th }}$ centuries music underwent numerous fundamental transformations. So, music for violin and harpsichord at different times and in different European national schools could be interpreted as: 1) solo violin with a harpsichord continuo; 2) violin solo with harpsichord accompaniment colla parte; 3) harpsichord solo with violin accompaniment (ad libitum); 4) harpsichord solo featuring obligato violin.

The colla parte method ("together with the musical line"), first mentioned in the treatise "Tratado de Glosas sobre Clausulas y ortros generos de puntos en la musica de Violones" (1553) by Diego Ortiz. It performes itself as a technique of "applying dissimilar, but coinciding in voices and parts timbres" 27 , known since ancient times and widely used in vocal practice of the Middle Ages, echoes of which are noticeable even in Bach works.

The "from intavolatura" method (intavolatura - introduction to the tablature, that is, to the score) means the transfer of one or more melodic voices to an accompanying harmonic instrument (organ or harpsichord). The genesis of this method, as well as its name, is associated with the vocal-choral

26 Polskaya I. I. (2001). The Chamber Ensemble: History, Theory, Aesthetics: Monograph. Kharkov: KhDAK.

${ }^{27}$ Bialyj I. (1989). From the History of the Piano Trio: Genesis and the Formation of the Genre. Moscow: Muzyka, p. 14. 
practice of the 17th century. In the process of asserting the dominance of an ensemble model with the participation of continuo (the first half of the $17^{\text {th }}$ century), the "from intavolature" method (duplication of melodic instruments parts in the clavier tablature) was widely distributed in chamberinstrumental music, and largely responded the needs of performing practice ("replacement" of absent musicians). In the practice of a chamber ensemble with a clavier participation, the application of the "from intavolature" principle meant the transfer of a one-voice string instrument melody to a clavier part. The voices of the melodic instruments, respectively, "were entrusted to the right hand, which was thus freed from the digital bass chords" 28 . This method was especially often used in English music (in the works of John Jenkins (1592-1678), John Cooper (also Giovanni Coprario or Coperario, ca. 1570-1626), William Laves (1602-1645) ${ }^{29}$, etc.).

The transformation of an instrumental ensemble by intavolatura method was carried out in different ways, the most important of which are: 1) the division of two upper voices of the trio and transfering one of them to the clavier. As a result a duet of a melodic instrument (violin) and clavier with a written two-voice part is created; 2) replacing the instrumental trio with two harpsichords with playing the parts of the first violin and bass on one of them, and the parts of the second violin with the same bass on the other.

The first type of an ensemble transformation by the intavolatura method is widely represented in many trio sonatas, in particular, the Sonata for organ (or spinet) and violin (or cornet) by Biagio Marini, Toccate for spinet (spinettino) and violin by Girolamo Frescobaldi, Sonata for violin and obligate cembalo by Johann Pachelbel and Sonata for gamba and concert cembalo by George Frideric Handel. The second type of intavolatura, associated with the transformation of the trio into a duet of two harpsichords, is embodied primarily in the works of François Couperin (in "The Apotheosis of Lully" and "The Apotheosis of Corelli").

One of the most important and most specific genre models of the Baroque era, the formation of which took place throughout the $17^{\text {th }}$ century, was a chamber-instrumental ensemble model "clavier - melodic instrument - bowed bass", originally based on the principle of duplication of a clavier bass with a bow instrument.

Its formation was marked by the appearance in 1610-1620 the first compositions for solo violin and general bass performed by a keyboard

${ }^{28}$ Bialyj I. (1989). From the History of the Piano Trio: Genesis and the Formation of the Genre. Moscow: Muzyka, p. 15.

${ }^{29}$ Meyer, Ernst H. English chamber music, the history of a great art from the middle ages to Purcell. London, 1946. 
instrument and bowed bass (cello or viola da gamba). Compositions of this kind were created for two obligate voices, but were intended for three instruments. The leading, dominant role in the ensemble belonged to the solo violin. The harpsichord and bowed bass performed the functions of a harmonic instrument, which in fact duplicated the lower voice of a clavier part. This method, which soon became traditional one, had a huge impact on the crystallization process of a chamber-clavier ensemble genres and functionally predetermined the appearance of a duet and trio genres. The principle of a melodic instruments' voices duplication in an ensemble was widely used not only in the clavier, but also in organ performing practice.

In parallel with the wide dissemination of these functional duplication methods, already in the middle of the $17^{\text {th }}$ century the opposite intra-ensemble role setting began to take shape, due to the tendency of the string bass to a certain independence. This trend in European countries art manifested itself in different ways. For example, the German chamber-ensemble music was characterized by a functional orientation on the violin solo sonata model and the wide usage of viola da gamba as a string bass. These are, in particular, 12 sonatas for violin, viola da gamba and clavier by Johann Rosenmüller (1688), 12 sonatas for violin, viola da gamba and clavier by Johann Philipp Krieger (1693), 7 sonatas for violin, viola da gamba and clavier by Dieterich Buxtehude (1696).

At the same time, in the Italian ensemble tradition of the late $17^{\text {th }}$ century, another genre of an ensemble modification was formed. Its inherent features was the participation of a clavier continuo, based on the model of an instrumental concerto. Its most significant difference is the activation of a cello's ensemble functions as a violin full partner. This variety of an ensemble is vividly presented in Sinfonia for violin, cello and basso continuo (ca. 1670) by Alessandro Stradella, Sonata for violin solo, obligato cello and cembalo (late $17^{\text {th }}$ century) by Giuseppe Torelli, Sonata da camera for violin, cello and cembalo op. 3 (1696) by Antonio Veracini ${ }^{30}$ etc.

The tendencies of a bowed bass relative independence (often by coloring the clavier basso continuo) and the usage of a cello in an ensemble were reflected in numerous compositions (by Henry Purcell, Tarquinio Merula) by the means of a "concerto" cello additional part. The main historical achievement of an Italian chamber ensemble trio sonata in its functional role aspect was the tendency to unify three equal ensemble members in the absence of a decisive factor in this unity - the written part of the clavier, with the appearance of which as an obligate ensemble component $\left(40^{\mathrm{s}}\right.$ of the

30 Wasielewski, W. J. von. Die Violine im 17 Jahrhundert und die Anfänge der Instrumentalcomposition. 1. Ausgabe Bonn, 1874. Bologna, 1969. S. 78-80. 
$18^{\text {th }}$ century) a cardinal turn in the evolution of the chamber-clavier ensemble had occurred.

In the $17^{\text {th }}-18^{\text {th }}$ centuries, genre evolution process of a chamberinstrumental ensembles with the participation of a clavier directly related to the formation and development of the following fundamental typological communicative models of functional role interaction: 1) a clavier ensemble model with the leading role of a melodic instrument; 2) a model of a clavier ensemble with the leading role of a keyboard instrument; 3) a clavier ensemble model in which melodic and harmonic instruments balance each other; 4) the model of a clavier ensemble, where the tendency to equal participation of various instruments and to the individualization of their roles had appeared.

The first of these models is most widely represented in Baroque solo sonatas for a solo melodic instrument (primarily a violin) with a clavier continuo accompaniment. After a long historical development, it gradually transformed into an ensemble of solo melodic instruments with a piano accompaniment (often quite developed).

The second ensemble model is inextricably linked with the evolution of the clavier sonata genre accompanied by melodic instruments (and possibly bowed bass) ad libitum or obligato. The seventeenth and eighteenth centuries are the heyday of such a clavier ensemble. Echoes of this genre model are still felt in the music of the beginning of the $19^{\text {th }}$ century.

The third mentioned model is inherent to trio sonatas intended for execution by various instrumental groups with a participation of the clavier continuo. Among the numerous trio sonatas, clavier trios attracts particular attention. According to that era terminology, they were often called "duets" for two melodic (usually string) instruments and the continuo clavier (or melodic instrument, continuo and bowed bass).

The fourth, and the most important for the subsequent evolution of a chamber ensemble genres model, had just begun to take shape at the baroque era.

Thus, in functional and hierarchical specifics of baroque ensembles, the communicative features of their functioning, directly associated with an action of various communication trends, were directly embodied. Some role-playing models of an ensamble were based on the inequality of solo melodic instrument (instruments) and the accompanying harmonic instruments (one or several) performing the accompaniment functions. In other ensemble models, the focus was on the dialogue aspiration, interaction and the relatively equal role participation of melodic voices in an ensemble. These trends, originated in Baroque music, fully developed in the mature ensemble culture of Viennese classicism, romanticism, and subsequent artistic trends and styles of the $19^{\text {th }}-20^{\text {th }}$ centuries. 


\section{Baroque ensemble genres: Genesis of the Clavier Ensemble}

A striking example of an ensemble genres historical formation during the Baroque era is the process of a clavier ensemble creation.

The genesis of a clavier ensemble in various modifications and its genre formation, crystallization of specific qualities are closely interconnected with musical-aesthetic and organological transformations in the cultural and historical context of the late $17^{\text {th }}-18^{\text {th }}$ centuries. During this period, the previously existing instruments (various types of claviers) were improved, new ones appeared (piano, invented in 1709 by Bartolomeo Cristofori (1655-1732). A turbulent process of experimentation was taking place in the field of timbre-phonic capabilities, instruments outward, etc.

Important sociocultural determinants of the clavier duet's birth are the general increase of an instrumentalism role, which led to a chamberinstrumental forms of concert flowering and family music-making, especially ensemble ones, in the hierarchy of which various duets took the leading place, as well as the tremendous rise of a clavier art and the basic role of a harpsichord (continuo) in the Baroque chamber music.

Carl Philipp Emanuel Bach (1714-1788), describing in the preface to the treatise "Versuch über wahre Art das Klavier zu spielen" (1753) the main areas of various keyboard instruments application, indicates: "Of all the clavier's clans $<\ldots>$ till nowadays, $<\ldots>$ harpsichords and clavichords have been the most successful. The first is used when playing together on many instruments, the second for playing solo. The latest pianos, if they are of good quality, $\langle\ldots\rangle$ are suitable for solo playing and for collaboration, if not many instruments are involved"31. At the same time, according to E. Braudo, all the "pre-piano" keyboards were associated with an ensemble tradition, and the harpsichord was "of exceptional importance as an accompanying instrument and, at the same time, until the middle of the 18 th century $<\ldots>$ it served as the only solo keyboard instrument ${ }^{\text {"32. }}$.

In the $17^{\text {th }}-18^{\text {th }}$ centuries both main types of a clavier ensemble arise and begin to develop gradually - on one or several (different) instruments. (The genre crystallization of these ensemble types - already piano - occurs only in the era of classicism at the end of the 18th century.)

The early stage of this process ( $18^{\text {th }}$ century) is characterized by the fact that genre formation of the clavier ensemble took place "not in one, but in several representative directions related to the performance on various

${ }^{31}$ Bach, C. Ph. E. Versuch über die wahre Art das Clavier zu spielen. I Teil. Berlin, 1753, p. 2 .

\footnotetext{
${ }^{32}$ Braudo E. (1924). Basics of Material Culture in music. Moscow: Novaya Moskva, p. 115.
} 
keyboard instruments - the virginal, spinet, harpsichord"33. This process took place almost simultaneously in England, France, Germany, while different composer and performing schools developed their own versions of the organological solution of an ensemble problems.

As a result of this long process of quantitative and qualitative (organological) stabilization of the clavier ensembles performing groups, the formation and subsequent genre differentiation of their main types multiclavier and monoclavier ensembles (author terminology $\mathrm{y}^{34}$ ) was originated. The first of them is an ensemble of two or more performers on two, three or more claviers; the second is an ensemble of two or more performers on one clavier, first of all - a four-handed clavier duet ${ }^{35}$.

The genre of monoclavier duet formation was determined by the organological transformations of keyboard instruments related to different methods of increasing the volume of their keyboard and occurring in two main directions - "horizontal" and "vertical"

The principle of "horizontal keyboard expansion of the sound volume of keyboard instruments" ${ }^{37}$ is associated with the appearance in the Baroque era the so-called double virginal (spinet), intended to play in an ensemble with other keyboard instruments representing a parallel horizontal "connection of two the same type virginals (spinet) or incorporation of a regular virginal with the smaller one, tuned an octave higher" ${ }^{38}$. E. Braudo notes that the smallest of them "tuned an octave above the church tone, larger instruments had a quint higher tune, and only the largest were tuned normally; at the same time, the quint instruments were connected only with large strong main ones" ${ }^{39}$. Instruments of this kind made it possible for performers to "play either singly (two hands) or together (four hands), while the volume of the keyboard as a whole in fact doubled" keyboard is, in particular, the spinet made by the famous clavier master Hans

33 Polskaya I. I. (1992). The development of the Piano Duet Genre in Austro-German romantic music (PhD), St. Petersburg: N. A. Rimsky-Korsakov St. Petersburg State Conservatory, p. 25.

34 Polskaya I. I. (2001). The Chamber Ensemble: History, Theory, Aesthetics: Monograph. Kharkov: KhDAK.

${ }^{35}$ Ibid, p. 124.

${ }^{36}$ Polskaya I. I. (1992). The development of the Piano Duet Genre in Austro-German romantic music $(\mathrm{PhD})$, St. Petersburg: N. A. Rimsky-Korsakov St. Petersburg State Conservatory, pp. $25-26$.

${ }^{37}$ Ibid, p. 25

${ }^{38}$ Ibid, p. 25.

${ }^{39}$ Braudo E. (1924). Basics of Material Culture in music. Moscow: Novaya Moskva, p. 108.

40 Polskaya I. I. (1992). The development of the Piano Duet Genre in Austro-German romantic music (PhD), St. Petersburg: N. A. Rimsky-Korsakov St. Petersburg State Conservatory, pp. 25-26. 
Ruckers, where "the keyboards $\langle\ldots\rangle$ are not located parallel to each other $\langle\ldots\rangle$, but nearby at some distance" ${ }^{, 41}$. The image of this unique tool, stored in the Kensington collection, is available in E. Braudo's book ${ }^{42}$.

This principle led to the development of a multi-clavier type of an ensemble, involving playing on several harpsichords or spinets, and laid the foundations for the unique kind of an ensemble art formation - a monoclavier (subsequently mono-piano) ensemble (duet).

The establishment of a horizontal-type monoclavier ensemble is primarily associated with the English virginal's tradition. Duets for two performers at the same virginal appear for the first time in the works of English virginalists of the $17^{\text {th }}$ century. The earliest surviving clavier duets of this type are "A Fancy for two to play" by Thomas Tomkins (1572-1656), "A Verse for two to play" by Nicholas Carleton (also Carlton) (ca.1570? -1630), as well as "A Battle, and no Battle" by William Bird (1543-1623). The last of these plays is intended to be performed in three hands, while "the lower voice is basso ostinato (on the subject of a signal for the battle), the upper ones are updating by varying",43.

Another type of an ensemble monoclavier art of the Baroque era was "vertical increase of the instrument's keyboard sound volume associated with playing on a two-manual harpsichord" 44 . Duet compositions intended for a two-manual harpsichord are more often found in the works of German school compositors - Johann Sebastian Bach, George Frideric Handel, Johann Christoph Friedrich Bach (1732-1795).

In $17^{\text {th }}$ century France, the formation and development of both clavier ensemble genre types (monoclavier and multiclavier) was indirectly associated with the abovementioned method of transformation by means of intravolature - using "interchangeable instrumental compositions that are not permanently fixed" ${ }^{45}$. A typical example of this kind is the genre-functional transformation of an instrumental trio with a harpsichord continuo into a duet of two harpsichords (and vice versa).

The emergence of such a method of clavier duet formation is associated with the name of François Couperin (1668-1733), in whose work it received its most vivid embodiment.

F. Couperin himself discloses the mechanisms for implementing this process in the "Notice to L'Apotheose de Lully": "This trio, as well as "L'Apothêose de

${ }^{41}$ Braudo E. (1924). Basics of Material Culture in music. Moscow: Novaya Moskva, p. 110.

${ }^{42}$ Ibid, p. 111.

${ }^{43}$ Sorokina E. G. (1988). The Piano Duet: A History of the Genre. Moscow: Muzyka, p. 12.

44 Polskaya I. I. (1992). The development of the Piano Duet Genre in Austro-German romantic music (PhD), St. Petersburg: N. A. Rimsky-Korsakov St. Petersburg State Conservatory, p. 26.

${ }^{45}$ Ibid. 
Corelli" and the complete collection of the trios, which I hope to perform in $<\ldots>$ July, can be performed on two harpsichords, as well as on any other instruments. I play them quite successfully with my family and my students as well, performing the upper part and bass on one harpsichord, and the second upper part and the same bass on the other in unison with the first harpsichord. To be truthful, it's necessary to have two copies of notes instead of one, as well as two harpsichords. However, I often find it easier to combine two instruments than four people who are professionally involved in music. You can use two spinets in unison, but this gives less effect" 46 .

The principle of interchangeability in Cuperin's clavier suites also extends on the choice of performance method and type of a clavier ensemble - on one or two harpsichords. This is clearly manifested in his so-called "croisées" plays ("Pièces croisées"), the specifics of the texture and spatial solution of which lies in possibility of free choice of performance method (on one or two harpsichords; on one harpsichord or spinet with one keyboard; on one harpsichord or spinet with two keyboards), as well as the participants group choice (duet or solo).

In the preface to the third collection of clavier compositions, François Couperin wrote about the performance of the croisées-plays: "Compositions with this name should be performed on two keyboards, one of which should sound muffled by changing the registers. Those who have a harpsichord with one keyboard or spinet will play the upper part as it is indicated, and the bass part an octave lower; if the bass part cannot be lowered by an octave, the upper part have to be increased by an octave" ${ }^{47}$. At the same time, when playing "croisées" plays on a two-manual harpsichord, a vertical increase in the sound volume of the instrument keyboard occurs, which also creates opportunities for playing keyboard ensembles (duets) together on one instrument - four- or three-handed (depending on the presence of a bass doubling or without him).

This principle of interchangeability of string and keyboard instruments was reflected in the works of F. Couperin ("L'Apotheose de Lully", "L'Apothêose de Corelli" and others), as well as in the works of other French musicians of the $17^{\text {th }}$ century - representatives of his composing and performing school.

Thus, the clavier ensemble genre formation took place in close interdependence with the development of different keyboard instruments, which had different spatial and timbre-register capabilities, actively influencing on the performance methods formation and on the texture features of an ensemble crystallization.

\footnotetext{
${ }^{46}$ Couperin, Francois. The art of playing the harpsichord. Moscow: Muzyka, pp. 73-74.

${ }^{47}$ Ibid,p. 68.
} 


\section{CONCLUSIONS}

In the Baroque era, European music passed through the emergence of an instrumental ensemble genre invariant. The process of a contemporary chamber-ensemble genres formation was distinguished by the semantic integrity, unification of development paths and methods - and a rare variety of specific ways and options for their embodiment, freedom of all genre's transformations and interactions. The principle of global variability, variation, transformation of all possible genre parameters, which manifested itself at all levels of an ensemble culture functioning, seen as fundamental in the specifics of the baroque stage of an ensemble genres evolution.

Along with the existence of the Middle Ages tradition of interchanging instruments, in baroque ensemble performance, more and more new criteria are approved, including the new approach to instrumental music appearance, new principles based on the consolidation of genre specificity.

A characteristic feature of this period's music is a kind of syncretism, the undifferentiation of performing genres system (solo, ensemble, orchestral), which had just begun to take shape. The lack of a clear division between solo and ensemble genres to a certain extent persists until the end of the 18th and even the beginning of the 19 th centuries.

In the music of the $17^{\text {th }}-18^{\text {th }}$ centuries the term solo was applied both to solo (sole) performance as such, and to ensemble performance with an accompaniment (two or three members) - provided that only one instrument is soloing in an ensemble. A similar interpretation of a solo concept inherent to the musical consciousness of that era is based on 1) the non-differentiation of ideas about the genre-functional and communicative nature of solo and ensemble performance and on; 2) the unprincipled role of quantitative factors of genre formation.

Baroque artistic practice is characterized by performing duplication of various ensemble parts (both quantitative - with an increase in the number of the same name instruments, and qualitative - multi-timbral). In chamberensemble music of this era, a whole series of typical functional-role communicative models has developed.

A huge role in baroque ensemble music was played by the string-keyboard instruments, especially harpsichord, which performed the functions of 1) a solo (concert) instrument; 2) an equal participant in the clavier duet; 3) basso continuo (in an ensembles with string and / or wind instruments).

The most important features of the genre formation of the Baroque era chamber ensemble are: 1) the semantic non-differentiation of an ensemble compositions, which makes it possible for various timbre changes in the genre invariant (qualitative and quantitative); 2) the establishment of "parallelvariant" ensemble parts performance tradition, an equal coexistence of several timbre modifications; 3) typification of a quantitative instrumental voices 
composition (the dominance of the trio principle) with complete freedom of their real performing ensemble embodiment; 4) approval of the harpsichord as an obligatory member of an ensemble, performing the supporting, fundamental role of continuo, as well as an independent participant in the clavier duet; 5) the gradual individualization of the character and ensemble functions of each of the melodic voices.

Important prospects for the further scientific exploration are the development of phenomenological, genre-semantic and system-genre directions of the specified era chamber ensemble, related to the theoretical comprehension of the ways of its historical evolution and typological specificity of the main genre varieties and genre functional models determination, organological, structural-functional and communicative features, textural and performance specificity.

\section{SUMMARY}

The article is devoted to the problems of genre specifics and typology of the chamber ensemble of the Baroque era. The object of research in the article is chamber music of the Baroque era. The aim of this study is the conceptualization of the phenomenon of the Baroque chamber ensemble and the typologization of its genre manifestations. The research methodology is based on an integrative combination of general scientific and special musicological methods and is based on the principle of the unity of historical and theoretical approaches. It is in the Baroque era that the archetype of a modern chamber ensemble begins to form. The main genres of a chamberensemble baroque music were Sonata da chiesa and Sonata da camera. The dominant structural-genre models of a $17^{\text {th }}$ century chamber music are solo sonata and trio sonata. Historical differences in the interpretation of the concepts of "solo" and "trio" in baroque music are associated with a number of performers and ensemble parts. A significant role in the process of crystallization of baroque chamber ensembles was played by the methods of genre transformation "from intavolature" and "from colla parte". Baroque music is characterized by an ensemble model "clavier - melodic instrument bowed bass", originally based on the principle of duplication of clavier bass with a bow instrument. The fundamental typological functional-role models of a baroque ensemble are: 1) the clavier ensemble model with the leading role of a melodic instrument; 2) a model of a clavier ensemble with the leading role of a keyboard instrument; 3) the clavier ensemble model in which melodic and harmonic instruments balance each other; 4) the clavier ensemble model with a tendency to equal participation of different instruments and to individualization of their roles. The historical specifics of an ensemble genres formation during the Baroque era is revealed. The main peculiarities of solo and ensembles musical genre's growing of this period are analysed. The ways 
of forming the genre invariant of the instrumental ensemble in the Baroque era are indicated. The basic principles of genre differentiation in ensemble music of baroque are considered. The organological specifics of baroque ensembles, due to the instruments interchangeability in the ensemble, is revealed. The general characteristic of the main functional-role models of a chamber ensemble of the Baroque era is given. The semantic specifics of the "solo" concept in the Baroque music is revealed. Organological and communicative features of a clavier ensemble formation were also identified.

\section{REFERENCES}

1. Bach, Carl Philipp Emanuel (1753). Versuch über die wahre Art das Clavier zu spielen [The Experience of the true Art of the Clavier Playing]. Part I. Berlin: Verlegungdes Auctoris. (in German).

2. Bialyj I. (1989). Iz istorii fortepiannogo trio: Genezis i stanovlenie zhanra [From the History of the Piano Trio: Genesis and the Formation of the Genre]. Moscow: Muzyka [Music]. (in Russian).

3. Braudo E. (1924). Osnovy material'noj kultury $v$ muzyke [Basics of Material Culture in music]. Moscow: Novaya Moskva [New Moscow]. (in Russian).

4. Bukofzer, Manfred F. (1964). Music in the Baroque Era: From Monteverdi to Bach. London: J. M. Dent\&Sons Ltd. (in English).

5. Couperin, Francois. Iskusstvo igry na klavesine [The art of playing the harpsichord]. Moscow: Muzyka [Music]. (in Russian).

6. Ginzburg L. S. (1979). Kamernaja muzyka v sovremennoj muzykal'noj praktike [Chamber Music in the modern musical practice]. Kamernyj ansambl':Pedagogika I ispolnitel'stvo [Chamber Ensemble: Pedagogic and Performing Art]. Moscow: Muzyka [Music], pp. 160-167. (in Russian).

7. Dapkviashvili T. (1989). Kamernye instrumental'nye ansambli I osnovnye prinzipy ansamblevogo ispolnitel'stva [Chamber instrumental ensembles and basic principles of ensemble performance]. Tbilisi: Helovneba. (in Russian).

8. Hurd, Michael (1968). An outline History of European Music. London: Novello. (in English).

9. Ivanov-Boretskiy M. V. (ed.) (1934). Materialy $i$ dokumenty po istorii muzyki [Materials and documents on the history of music]. Vol. 2: XVIII vek (Italiya, Frantsiya, Germaniya, Angliya) [XVIII century (Italy, France, Germany, England)]. Moscow: Muzgiz [State Music Publishing House]. (in Russian).

10. Meyer, Ernst Herman (1946). English chamber music, the history of a great art from the middle ages to Purcell. London: Lawrence\&Wishart. (in English). 
11. Polskaya, I. I. (2004). Zhanrovaja spetsifika kamernogo ansamblia epohi Barokko (semanticheskij I funktsional'no-rolevoj aspekty) [The Genre Specifics of the Chamber Ensemble of the Baroque era (semantic and functional role aspects)]. The Bulletin of the International Slavic University. Series: Art Studies, no. 1, pp. 42-46. (in Russian).

12. Polskaya, I. I. (2001). Kamernyj ansambl': istorija, teorija, estetika [The Chamber Ensemble: History, Theory, Aesthetics: Monograph. Kharkov: KhDAK. (in Russian).

13. Polskaya, I. I. (2003). Kamernyj ansambl': teoretiko-kul'turologicheskie aspecty [Chamber Ensemble: theoretical and culturological aspects] (Hab. Dr.), Kyiv, P. I. Tchajkovsky National Musical Academy of Ukraine. (in Russian).

14. Polskaya, I. I. (1992). Razvitie zhanra fortepiannogo dueta v avstronemetskoj romanticheskoj muzyke [The development of the Piano Duet Genre in Austro-German romantic music] (PhD), St. Petersburg: N. A. RimskyKorsakov St. Petersburg State Conservatory. (in Russian).

15. Polskaya, I. I. (2012). Kamernyj ansambl' [Chamber Ensemble]. The Encyclopedia of Modern Ukraine. Vol. 12. Kyiv: Institute for Encyclopedic Research by National Academy of Sciences of Ukraine, pp. 112-114. (in Ukranian).

16. Sorokina E. G. (1988). Fortepiannyj duet: Istorija zhanra [The Piano Duet: A History of the Genre]. Moscow: Muzyka [Music]. (in Russian).

17. Stevens, Denis (1970). Duet Sonatas without wind instruments (from 1700). Chamber music (ed. by Alec Robertson). London: Penguin Books Ltd, pp. 253-287. (in English).

18. Wasielewski, W. J. von. (1969). Die Violine im 17 Jahrhundert und die Anfänge der Instrumentalcomposition [The Violin in the 17th century and the Beginnings of Instrumental Composition]. (1. Ausgabe Bonn, 1874). Bologna: Forni. (in German).

\section{Information about the author: \\ Irina Polskaya,}

Doctor of Art Criticism (hab. dr.), Habilitated Professor, Professor at the Department of History and Theory of Music

Kharkiv State Academy of Culture, Kharkiv 4, Bursatski Uzviz, Kharkiv, 61057, Ukraine orcid.org/0000-0003-3546-5900 